\title{
Brittle and Ductile Fracture Mechanics Analysis of Surface Damage Caused During CMP
}

Terry A. Ring ${ }^{\ddagger}$, Paul Feeney, David Boldridge, Jaishankar Kasthurirangan, Shoutian Li, and James A. Dirksen

Cabot Microelectronics Corporation

870 Commons Drive

Aurora, IL 60504

and

${ }^{£}$ Chemical Engineering Department

University of Utah

50 S. Central Campus Drive, MEB3290

Salt Lake City, UT 84112

\section{Abstract}

This work reviews the mechanical properties and fracture mechanics of materials important in the manufacture of multilayer interconnects on silicon chips in order to understand surface damage caused during chemical mechanical polishing (CMP). It 
gives an explanation for chatter marks, surface flaking in interlayer dielectric material (ILD) and rolling indenter and plastic plow lines in copper on the wafer surface during CMP of silicon chips.

\section{Introduction}

Chemical mechanical planarization is also called chemical mechanical polishing (CMP). These terms evoke the combination of chemical and mechanical aspects in the polishing and planarization of silicon chips. There have been several papers over the years that discuss the chemical dissolution ${ }^{12}$, of surfaces being polished and there has been less

work on the mechanical wear ${ }^{3},{ }^{4}$, of a surface being polished until more recently. There have not been many papers that discuss the mechanical aspects of scratching and surface damage in CMP.

CMP is used multiple times during the production of today's silicon chips as there are multiple layers of wiring required to connect the more than one billion transistors per square centimeter in a modern silicon chip to the outside world. CMP uses a suspension of abrasive particles as the contacting medium between a polymeric pad and the wafer surface. In addition to material selective removal at the wafer surface, CMP is used to produce flat wafer surfaces that allow small features to be in focus during photolithography. CMP slurries, if not very carefully produced to eliminate impurity particles, have the propensity to cause surface damage to the wafer. Surface damage can be trivial or it can be catastrophic as when a wire line or dielectric layer is cut by a scratch. Surface damage during CMP is a major concern of chip manufacturers. The 
reasons that this is the concern are: 1) there are more and more wiring layers needed for newer generations of chips, 2) the layers are thinner with each new generation of chips and 3) the size of the surface damage that causes catastrophic wiring failure is smaller with new generations of chips.

With each wiring layer there are several CMP steps needed to create that layer. At a minimum there is one copper CMP step and one dielectric CMP step. There may also be a step where the barrier layer is polished. With each CMP step there is a finite probability, $\mathrm{P}_{\mathrm{Cu}}$ or $\mathrm{P}_{\mathrm{D}}$, that surface damage will cause a wiring failure in a die. This probability allows the calculation of a process yield given by:

Yield $=\prod_{i}^{N}\left(1-P_{C u}\right)^{n}\left(1-P_{D}\right)^{m}$

where $\mathrm{n}$ is the number of copper CMP steps and $\mathrm{m}$ is the number of dielectric steps for the construction of a single layer the wiring layer, signified by $\mathrm{i}$ in the following equation, and $\mathrm{N}$ is the number of wiring layers. Assuming that $\mathrm{n}=1, \mathrm{~m}=1$ and $\mathrm{N}$ is 8 for a modern chip small values of $\mathrm{P}_{\mathrm{Cu}}$ and $\mathrm{P}_{\mathrm{D}}$, say 0.01 and 0.001 respectively, can lead to a process yield of $91 \%$ which is not uncommon. This low yield has lead to a reliance on inspection after each step and layer reworking if too many surface flaws are observed. Both inspection and reworking of the surface increase the cost of chip processing significantly. To reach six sigma levels for chip manufacturing with chip failure rates of only 3.4 in $1,000,000$, the catastrophic flaw probability, i.e. $\mathrm{P}_{\mathrm{Cu}}$ and $\mathrm{P}_{\mathrm{D}}$ in this 8 -layer 
metallization example, must be lowered to 1 in $10^{7}$, an effectively unattainable flaw probability with present CMP technology.

As we move to smaller line sizes and to more layers of wiring requiring more CMP steps, CMP surface defects will need to be lowered significantly in their depth, area of damage and number per $\mathrm{cm}^{2}$ so that they do not destroy the ever smaller components, wires and insulting layers. This paper is devoted to understanding of surface defects and the fracture mechanics that causes them. The onset of surface damage is accompanied by the observation of increased concentration of large particles ${ }^{6}$. These large particles can be impurities of slurry production, dried crusts that fall into the slurry during production and use or produced during CMP as wear debris.

\section{Introduction to Mechanical Properties and Fracture Mechanics as Applied to CMP}

In CMP processes, surface damage can take place because CMP uses a slurry of abrasive particles. At the wafer surface there are areas of metal (copper) and areas of dielectric insulating materials, (borosilicate glass, silicate glass produced by chemical vapor deposition, Low-K, a carbon loaded silicate; and barrier layer materials, e.g. various nitrides and silicides). There are two general types of materials based upon their mechanical properties - ductile materials and brittle materials. Metals are the classic examples of ductile materials where they can be deformed without failure. Glasses are the classic examples of brittle materials - they shatter. These properties are contrasted in 
the stress strain curves shown in Figure 1a \& b. In Figure 1a, we see the stress strain curve for an annealed sample of polycrystalline copper. At elongations, $\varepsilon$, less than 0.0008 corresponding to the linear portion at the y-axis, there is a linear (elastic) region with a slope given by Young's modulus for the material. Above the linear region there is a plastic zone where the slope of the curve decreases with increasing elongation up to the tensile strength. At elongations above the tensile strength there is a decrease in the stress to the point of rupture at an elongation of $53 \%$, an enormous amount of stretching before failure. In Figure $1 \mathrm{~b}$ we see the stress strain for borosilicate glass. There is a linear (elastic) region up to an elongation of only 0.0012 , the point of rupture. Thus we can see from these two figures the differences between ductile and brittle materials that are the two major components of the metallization layers of today's chips.

\section{Fracture Mechanics}

There are three surface fracture modes shown in Figure 2. In Irwin's notation ${ }^{7}$, mode I denotes a symmetric opening, the relative displacement between the corresponding sides of the opening being normal to the fracture surface, while modes II and III denote antisymmetric separation through relative tangential displacements, normal and parallel to the crack front, respectively.

The focus of fracture mechanics is on the tip of the crack identified by the end of the fracture lines in Figure 2 - any fracture mode. Much effort is expended to identify the stress intensity at the tip of the crack and a parameter traditionally calculated is the stress

intensity factor, $\mathrm{K}_{\mathrm{I}}, \mathrm{K}_{\mathrm{II}}$ or $\mathrm{K}_{\mathrm{III}}$, where the subscript refers to the mode of loading. In the 
following discussion, we will use Mode I loading almost exclusively for fracture toughness (with cracking) and for scratching and wear. When the stress intensity factor is larger than a critical value, e.g. $\mathrm{K}_{\mathrm{I}}>\mathrm{K}_{\mathrm{Ic}}$, the crack will enlarge. Before we proceed to this discussion, we need to discuss the formation of the crack or surface flaw. This is best done with a discussion of an indenter that may be considered a hard impurity particle forced into the surface of the wafer by a normal force provided by the pad as shown in Figure 3.

\section{II.1 Indentation}

During indentation a normal force is applied to an indenter placed at the surface. The indenter typically made out of a very hard material can have different shapes including sharp points and rounded spherical surfaces. As the force applied is increased, the surface under load initially deforms elastically under the load leaving behind an undamaged surface when the load is removed. Elastic deformation is referred to as Hertzian contact as Hertz developed an analytical solution for this type of contact, shown in Figure 3. Elastic deformation depends upon the elastic modulus of the material, E. A table of materials properties is given in Appendix A for common materials encountered in CMP. The elastic modulus can be predicted from first principles using molecular modeling if the crystal structure is known for the material. The stress distribution under a spherical indenter is shown in Figure 3. With a larger force, the load is too high and slip planes within the material are activated giving rise to plastic deformation, which leaves behind surface damage in the shape of the indenter's profile when the load is removed ${ }^{8}$, see Figure 4 (without the semi-circular crack). 
The normal load, $\mathrm{L}_{\mathrm{N}}$, needed to cause plastic deformation (without cracking) is a measure of the materials hardness, H. The hardness has several definitions depending upon the shape of the indenter. If the indenter is a sphere $\mathrm{H}_{\mathrm{B}}=\mathrm{L}_{\mathrm{N}} /\left(\pi \mathrm{d}^{*} \delta\right)$ where $\mathrm{d}$ is the diameter of the indentation and $\delta$ is its depth for Brinnell hardness and $\mathrm{H}_{M}=\mathrm{L}_{\mathrm{N}} /\left(\pi \mathrm{d}_{M}{ }^{2}\right)$ for Meyer Hardness where $d_{M}$ is the diameter of the dent. If the indenter is a square pyramid, the Vicker's Hardness is $\mathrm{H}_{\mathrm{V}}=1.8454 \mathrm{~L}_{\mathrm{N}} / \mathrm{a}^{2}$, where a is the corner-to-corner diagonal distance of the square mark in the surface, see Figure 5a. If the indenter is an elongated pyramid, the Knoop Hardness is $\mathrm{H}_{\mathrm{K}}=14.2 \mathrm{~L}_{\mathrm{N}} / \mathrm{D}^{2}$ where $\mathrm{D}$ is the maximum dimension of the indenter mark in the surface.

With even larger forces applied to the indenter, the surface fractures forms a semicircular or radial cracks into the surface directly under the point of the indenter, see Figure 4 and 5. The radial cracks, of size $\mathrm{c}$ (also $C_{R}$ in Figure 4), has a half-circle shape under the indenter protruding to a distance $\mathrm{c}$ away from the point of contact along the surface of the material in opposite directions.

A crack at the surface intensifies any stress, $\sigma$, placed upon the sample. The stress intensity factor, $\mathrm{K}_{\mathrm{I}}$, for a small surface flaw of size $\mathrm{c}$ is given by:

$$
K_{I}=Y \sigma \sqrt{c}
$$


where $\mathrm{Y}[=1.12 \sqrt{ } \pi]$ is a purely geometric constant. After indentation with very high load, $\mathrm{L}_{\mathrm{N}}$, resulting in cracking, the stress intensity factor associated with the residual stress field can be written as ${ }^{9}$

$$
K_{I}=\frac{\chi L_{N}}{c^{3 / 2}}
$$

where $L_{N}$ is the normal load, $c$ is the crack size and $\chi\left[=\beta(E / H)^{1 / 2}\right]$ is a constant associated with the material's properties, the elastic modulus $\mathrm{E}$ of the material, the hardness, $\mathrm{H}$, of the material given in Appendix A and the indenter shape characterized by $\beta[\sim 0.016]$. The final size of the crack, $c_{o}$, loaded to its critical point, $L_{c}$, is determined by the fracture toughness, $\mathrm{K}_{\mathrm{Ic}}$, of the material, a material property also given in Appendix A.

$$
K_{I c}=\frac{\chi L_{c}}{c_{o}^{3 / 2}}
$$

When there is an additional stress, $\sigma$, applied with mode I loading, there will be two contributions to the total stress intensity factor, given by ${ }^{10}$ :

$$
K_{I}=\frac{\chi L_{N}}{c^{3 / 2}}+Y \sigma c^{1 / 2} .
$$

The crack of size, $c$, will enlarge when $\mathrm{K}_{\mathrm{I}}>\mathrm{K}_{\mathrm{Ic}}$. 
Measuring the crack size associated with this additional load applied with an indenter allows the fracture toughness, $\mathrm{K}_{\mathrm{Ic}}$, to be determined experimentally. At loadings below the point of cracking and within the zone where only plastic damage occurs on the surface allows the hardness of a material to be determined experimentally. Microindenters may be used to characterize the mechanical properties of the different materials used to construct silicon chips when these mechanical properties have not been measured elsewhere.

\section{II.2 Scratching}

With CMP scratching, a hard object of a given shape is both forced into the surface and dragged across the surface of a material. This is the same geometry as that of an indenter shown in Figure 5 but an additional lateral force is used to drag the indenter along the surface of the material. Multiple hard objects simultaneously being forced into the surface and being dragged across the surface of a material is referred to as mechanical wear.

The resulting failure can be predicted by various mechanical wear (or scratching) equations depending upon the assumption of plastic deformation or brittle fracture, see Figure $6 \mathrm{a} \& \mathrm{~b}$. For a given material, the wear rate goes from reasonably low rates for plastic wear to orders of magnitude higher with brittle fracture. The wear rate transition occurs at a threshold normal load given by ${ }^{11}$ :

$$
\mathrm{L}_{\mathrm{Nc}} \sim 2 \times 10^{5} \mathrm{~K}_{\mathrm{Ic}}{ }^{4} / \mathrm{H}^{3}
$$


where $\mathrm{H}$ is the hardness of the surface being damaged and $\mathrm{K}_{\mathrm{Ic}}$ is its fracture toughness. The plastic and brittle fracture wear rates are discussed in the next two paragraphs.

\section{Plastic deformation}

The differential volume, $\mathrm{dV}$, of material removed per unit length, $\mathrm{dx}$, of the scratch depends upon the load of the abrasive point normal to the surface, $\mathrm{L}_{\mathrm{N}}$, and the mechanical properties of the materials comprising the surface ${ }^{12}{ }^{13}$ :

$$
\mathrm{dV} / \mathrm{dx} \sim\left(\mathrm{L}_{\mathrm{N}} / \mathrm{H}\right)
$$

where $\mathrm{H}$ is the hardness of the surface being damaged. This equation assumes that the abrasive point is harder than the material comprising the surface. The volume removed is plowed into a furrow onto the material's surface, see Figure 6a.

\section{Brittle fracture}

The differential volume, $\mathrm{dV}$, of material removed per unit length, $\mathrm{dx}$, of the scratch depends upon the load of the abrasive point normal to the surface, $\mathrm{L}_{\mathrm{N}}$, and the mechanical properties of the materials comprising the surface ${ }^{14}$ :

$$
\mathrm{dV} / \mathrm{dx} \sim(\mathrm{E} / \mathrm{H})^{4 / 5} \mathrm{~K}_{1 \mathrm{c}}{ }^{-1 / 2} \mathrm{H}^{-5 / 8} \mathrm{~L}_{\mathrm{N}}{ }^{9 / 8}
$$


where $\mathrm{E}$ is Young's modulus of elasticity, $\mathrm{H}$ is the hardness, $\mathrm{K}_{\mathrm{lc}}\left[=2 \mathrm{E} \gamma_{\mathrm{f}}\right]$ is the fracture toughness and $\gamma_{\mathrm{f}}$ is the surface energy for fracture. All of these material properties are for the surface being damaged as this equation assumes that the abrasive point is harder than the material comprising the surface. The volume removed in this case consists of the surface furrow as well as large pieces of the surface material being dislodged from the surface out to the point where the lateral cracks reach the surface, see Figure $6 \mathrm{~b}$. The above equations are consistent with experimental measurements for scratching wear and particle erosion within the limits of experimental accuracy ${ }^{15}$ and can be used to determine 1) the plastic wear rate of the pad during both pad conditioning and CMP, 2) the mechanical wear (plastic wear) rate of the copper surface in CMP and 3) the mechanical wear (brittle wear) rate of the ILD surface in CMP. These mechanical types of wear are $\underline{\text { not always desirable processes in CMP as they lead to surface defects. }}$

\section{II.3 Scratch Depth}

To determine the depth distribution of the scratches due to both abrasive and impurity particles, we consider each of these scratching particles to be attached to the tip of an asperity or if larger than an asperity to be pressed into the pad. Since we have a distribution of particle sizes for both the abrasive particles and the impurity particles and we have a distribution of forces caused by the height distribution of asperities on which the particles will reside, this gives a complicated scratch depth distribution. If in addition, the impurity particles are not spherical but angular, we will also have an additional distribution to consider - the distribution of radii of curvature for the point of 
the impurity particle in contact with the wafer surface. The depth of the scratch for an indenter of radius, a, depends upon the type of failure taking place at the wafer surface. Either plastic deformation or brittle fracture at the wafer surface can lead to scratching, as shown in Figure $6 \mathrm{a} \& \mathrm{~b}$. The plastic deformation scratch depth shown in Figure 5 and 6 is given by ${ }^{16}$ :

$$
b=\left(\frac{L_{N} E^{1}}{H^{2}}\right)^{1 / 2}(\cot \psi)^{1 / 3}
$$

where $L_{N}$ is the normal load applied to the indenter, $\left.\left.E^{\prime}\left\{=\left[\left(1-v_{1}^{2}\right) / E_{1}\right)+\left(1-v_{2}^{2}\right) / E_{2}\right)\right]^{-1}\right\}$ is the relative modulus of elasticity (or relative Young's modulus) for the materials in contact, 1 and 2, $\mathrm{H}$ is the hardness of the surface of the wafer, material 1 , and $2 \psi$ is the angle between opposite edges of the indenter, material 2. Note, there is load enhancement due to the hardness of the particles at the asperity tip compared to the polyurethane asperity itself. Its effect is felt in the $E^{`}$ term as $E_{2}$ is increased.

The depth of the radial cracks, see Figure 5b, gives the scratch depth for brittle fracture ${ }^{17}$ :

$$
c=C_{R}=\left[\xi_{r}\left(\frac{E^{\prime}}{H}\right)^{1 / 2}\left(\frac{L_{N}}{K_{I c}}\right)(\cot (\psi))^{2 / 3}\right]^{2 / 3}
$$

where $\mathrm{K}_{\mathrm{Ic}}$ is the fracture toughness of the surface of the wafer, material 1 , and $\xi_{\mathrm{r}}$ is a dimensionless constant with the value $0.037^{18}$ or $0.016^{19}$. 
There is a transition between plastic and brittle fracture scratching that takes place as the load is increased. The critical load at which this transition takes place is given by ${ }^{20}$ equation 6. Therefore, when the load on an impurity particle is less than $\mathrm{L}_{\mathrm{Nc}}$, plastic deformation will take place. When the load is on an impurity particle is greater than, $\mathrm{L}_{\mathrm{Nc}}$, brittle fracture will take place. Brittle fracture is by far the most destructive to the wafer surface as the lateral and radial cracks penetrate more deeply than the plastic deformation damage.

The impurity particle is forced by one (or more) of the pad asperities to be in contact with the wafer surface. There is a distribution of pad asperities onto which the impurity particles can be attached and still be in contact with the wafer. Depending upon the length of the pad asperity that the impurity particle is attached to and the size of the impurity particle, the load, L, acting on the impurity particle/wafer contact point can be determined. Greenwood and Williamson ${ }^{21}{ }^{22}$ have used exponential distribution functions to describe the rough surfaces. The contact area, $A_{\text {con }}$, and load, $L$, over the wafer, is obtained by integration of the asperity height from the distance between the wafer and the plane of reference in the pad, $\delta$ to infinity given below. An asperity will contact the wafer if its length, $\mathrm{z}$, is greater than $\delta$.

$$
\begin{aligned}
& A_{\text {con }}=\rho_{\text {asperities }} A_{\text {wafer }} \int_{\delta}^{\infty} \int_{0}^{\infty} \pi \beta(z-\delta) g(\beta) g(z) d \beta d z \\
& L_{N}=\rho_{\text {asperities }} A_{\text {wafer }} \int_{\delta}^{\infty} \int_{0}^{\infty} \frac{4}{3} E^{\prime} \sqrt{\beta}(z-d)^{3 / 2} g(\beta) g(z) d \beta
\end{aligned}
$$


In the above equations, $A_{\text {wafer }}$ is the surface area of the wafer assuming a flat surface, $g(x)$ is the distribution function for the asperity height, $z$, or the radius of curvature of the asperity, $\beta$, and E' is the effective Young's modulus defined below. The applied pressure is $\mathrm{L}_{\mathrm{N}} / \mathrm{A}_{\text {wafer }}$ and the average contact pressure is $\mathrm{L}_{\mathrm{N}} / \mathrm{A}_{\text {con }}$.

Equations 11 and 12 can be used to predict the size distribution of surface damage produced during CMP. In this analysis, the Greenwood, et. al. exponential distribution of pad asperities was characterized by the mean and standard deviation of the length of the asperities, and an area density of asperities with all asperities assumed to have the same radius of curvature at their tips. The pad asperity parameters used in this analysis were those measured by $\mathrm{Yu}$, et.al ${ }^{23}$ for a conditioned pad. The asperities press the impurity particles into the wafer surface creating a normal load that allows the depth of the surface damage to be predicted using equations 10 for a brittle material like the interlayer dielectric (ILD) and equation 6 for a ductile material like copper. Putting this all together, we find that the size distribution of scratches produced by the impurity particles is given in Figure 7. Here we see that the deepest scratches are formed by the largest impurity particles and the population of scratches decreases as the scratch depth increases for a given size of impurity particles. Brittle material does not have a plastic zone where plastic deformation scratching can take place so the ILD curves are only for brittle fracture surface damage. Since copper is a malleable material it deforms plastically so these copper curves are only for plastic deformation surface damage. Combining the analysis shown in Figure 7 with knowledge of the number and size distribution of impurity particles in a log-normal size distribution of particles, then the scratches 
produced by this distribution of impurity particles can easily be calculated by simply integrating over the impurity particle size distribution. The scratch population produced by the single impurity particle of a particular size is shown in Figure 7.

\section{II.4 Size distribution of Scratch Debris}

Another important aspect of scratching is the size distribution of debris material produced. In CMP these particles can be a new generation of impurity particles leading to enhanced scratching. We can determine this by considering the material flaked off the wafer surface due to brittle fracture damage, see Figure 8 and 9.

The material flaked from the surface by scratching has a thickness corresponding to the depth of the plastic layer, $b$, defined by equation 9 . The other dimension is related to the lateral crack length, $\mathrm{C}_{\mathrm{L}}$, defined by ${ }^{24}$ :

$$
\mathrm{C}_{\mathrm{L}}=0.096(\mathrm{E} / \mathrm{H})^{2 / 5} \mathrm{~K}_{\mathrm{c}}^{-1 / 2} \mathrm{H}^{-1 / 8}\left[1-\left(\left(\zeta_{\mathrm{o}} \mathrm{K}_{\mathrm{c}}{ }^{4} / \mathrm{H}^{3}\right) /\left(\mathrm{L}_{\mathrm{N}}\right)\right)^{1 / 4}\right]^{1 / 2} \mathrm{~L}_{\mathrm{N}}{ }^{5 / 8},
$$

where $\zeta_{0}$ is an order 1 dimensionless constant. Ideally, the shape of the flake is considered a wedge of a circle with the radius of the circle being $\mathrm{C}_{\mathrm{L}}$. Since the abrasive particles will have different normal loads and different point shapes (considering impurity particles) the debris particle size distribution will be broad. However, the debris particle size distribution can be predicted if the distribution of normal loads is known (assuming that the indenter shapes are spherical). One important point is that the size of the debris due to brittle fracture scratching is larger than the indenter tip causing the scratching, so that brittle fracture scratching produces new impurity particles larger than 
the original indenter that are likely to go on to make even large scratches quickly propelling the number and size of surface defects to high levels.

\section{II.5 Experimental Observations of Surface Damage and Comparisons with Predictions}

The surface of the wafer during the fabrication of any of the multiplayer interconnection layers has areas of metal and areas of dielectric exposed to the CMP slurry. The thickness of the layer and the width of a region of metal or dielectric are on the order of $100 \mathrm{~nm}$ in size with modern chips. Surface damage during CMP can cut through the thickness or the width of these features and cause the components that they represent to fail. For this reason, understanding and controlling surface damage during CMP is important.

V-shaped plastic deformation scratches in copper have been observed on wafer surfaces in cases with high levels of scratching, see Figure $9 a, b$ and $c$. The size of the $\mathrm{V}$ is on the order of 100's of nanometers in width. Since this is larger than the size of the abrasive particles, it is assumed that this is due to an impurity particle being normally loaded and dragged along the wafer surface. Furthermore as the impurity particle is dragged across the surface the depth of the $\mathrm{V}$ is different when the surface changes from tantalum to copper and vice versa. A plastic deformation scratch will form in a material when the stress imposed by the indenter is greater than the hardness of the material. In the case of copper this is $0.874 \mathrm{GPa}$ and in the case for tantalum this is $0.873 \mathrm{GPa}$ using data from 
Appendix A. Noting that the ILD in Figure 9a \& b is borosilicate glass (BSG), we know that the applied stress that caused the scratch in the copper layer but not in the BSG layer is $>0.874 \mathrm{GPa}$, (the hardness of copper and $<5 \mathrm{GPa}$ the hardness of BSG).

If a single impurity particle is large, hard and has multiple points of contact with the wafer surface it can be loaded with sufficient force by many pad asperities to cause multiple indenter points to be dragged across the surface simultaneously giving multiple parallel scratches as shown in Figure 9d. Each of the indenter points can be treated with the scratching equations presented in Section II.3, however, to apply these equations we would need to know how the load developed by the pad is distributed over the back of the impurity particle and the specific geometry of the hard points of contact with the wafer surface. This load redistribution will be specific to each of these very large impurity particles. This makes a simple analysis of the resulting scratching difficult. Another possible explanation of the multiple parallel scratches shown in Figure 9d are that a series of pores, similar size, has been produced in the deposited metal layer possibly associated with previous scratches at the underlying layer surface. During CMP these pores are uncovered leaving them open after a certain amount of removal.

Other types of copper plastic surface damage are shown in Figure 9e \& f where a random pattern of an irregular particle rolling across the copper surface is shown. In Figure 9e, the particle makes indentations as the particle rolls but the tips are broken during rolling altering the shape of the indentation marks as it rolls along. Figure 9f, shows an example of a plowing-rolling action of an impurity particle on a copper surface. 
Brittle surface damage in the BSG surface is shown in Figure $9 \mathrm{~g} \& \mathrm{~h}$. Here the brittle fracture lateral cracks are flaked away from the surface leaving behind an irregular surface. The pieces missing in the surface give rise to irregular flakes of BSG in the slurry - impurity particles that can go on to cause more damage on the wafer surface. In addition, there are repeated $\mathrm{C}$ patterns where there was no flaking of the surface along the trajectory of the scratch. These will be discussed later.

Various examples of CMP surface damage can be addressed by fracture mechanics analysis. An example is the series of indentations made by a rolling large non-symmetric impurity particle as seen in Figure 10. Here the particle rolls along the surface of the pad and when its sharp edge comes in contact with the wafer on its longer axis it is normally loaded by the pad with a significantly larger force causing an indentation. With the shorter axis in contact with the wafer surface there is not sufficient force to cause indentation. The indentations will take on the shape of the surface of the longer axis of the particle and be imbedded into the wafer surface according to the indenter equations, equation 9, if the load is below that for brittle fracture and equation 10 if the load is above this critical load. Measuring the depth and shape of the indentation shown in Figure 10, we can determine the force that must have been responsible for the indentation using equation 9 and the mechanical properties of the two surfaces in contact. The larger of the two repetitive spots shown in Figure 10 has a radius of the damage zone of $\sim 208$ nm. If we assume that an $\alpha$-alumina particle with a $60^{\circ}$ sharp edge on its elongated axis is responsible for the damage, then the force acting on the particle is $\sim 1.76$ dynes 
according to equation 9. And if we assume that a piece of BSG debris with a $60^{\circ}$ sharp edge on its elongated axis is responsible for the damage, then the force acting on the particle is $\sim 2.65$ dynes. If we assume that the impurity particle started its surface damage in the upper left hand corner of Figure 10, we can see that one sharp edge of the impurity particle is damaged after 12 roll events leaving behind a single surface indentation for roll events 13 through 15 . We can also determine some sense of at least two dimensions of the impurity particle by the distances between the repetitive indentations - the large axis is $4.17 \mu \mathrm{m}$ and the smaller axis is $1.25 \mu \mathrm{m}$.

A large number of rolling particle indenter scanning electron microscope (SEM) images have been analyzed for the length of the repeat distance, on average, and the width of the repeat structure, on average. These results have been reduced to distribution functions, which are given in Figure 11. In this figure we see that the surface damage structures produced during copper CMP using Cabot CMC 5000 slurry on $200 \mathrm{~mm}$ patterned wafers polished on a Mira CMP tool operated at a platen rpm of 57 and a wafer rpm of 63 . This surface damage has a lognormal distribution with a mean of 3 microns for the width and 4 microns for the length. These measurements allow an indirect characterization of the hard impurity particles present in CMP slurries or generated during CMP.

Another type of surface defect is shown in Figure 12. Here we see that the surface defect is repetitive and appears to form a $\mathrm{C}$-shaped crack in the surface of the wafer in the optical image of one of these chatter cracks in ILD materials. In this image the cracks are larger at one end and smaller at the other end of the repetitive line. The atomic force 
microscope (AFM) view of another chatter crack shown in Figure 12 shows repetitive Cshaped surface damage that is 10 's of nm deep with some individual cracks being deeper than others. Indeed the AFM stylus may not be able to completely probe the depth of a narrow crack, as it may be too narrow at its apex. The AFM image in Figure 12 appears to be of a chatter crack that has had some CMP polishing done on it after it was made and before the AFM image was taken since the surfaces are rather rounded. A sectional analysis of the AFM image is given in Figure 13. Here we see that the repetitive chatter cracks are $\sim 40 \mathrm{~nm}$ deep at they are deepest and have a repeat distance of $2 \mu \mathrm{m}$.

A rolling $2 \mu \mathrm{m}$ on edge angular particle with a C-shaped indenter tips could be causing these chatter cracks but it is not likely that there would be so many impurity particles with C-shaped indenter tips on them. Another explanation could be an angular indenter with a stick slip lateral action but it is not likely that the sticking would occur regularly it is more likely to occur randomly. In addition, we have seen that the same indenter that causes the flaking action of brittle fracture also sometimes makes the chatter cracks, see Figure $9 \mathrm{~h}$. As a result, an alternative explanation has been sought for chatter cracks. This other explanation can be simplistically viewed as that of a bouncing particle where the springiness of the pad causes the particle to bounce against the wafer surface. Bouncing may be initiated by an impurity particle that is sliding across the surface of the wafer entering into either a $v$-groove or flake in the wafer surface made during a previous scratching incident or a zone of surface buildup due to deposition that acts like a ramp. After the first bounce, the particle can have sufficient force when it hits the wafer surface to indent the surface of the wafer. This force is supplied by the elastic properties of the 
pad when the particle is pushed into it and then rebounds. Once the wafer surface is indented by an impurity particle, the lateral movement of the pad against the wafer forces the indentation to open a Mode I crack according to equation 5 where the applied force is supplied by the lateral elastic properties of the pad and the lateral motion of the wafer relative to the pad. This Mode I crack will open up under the indenter but lead to a combination Mode II-Mode III tear in the surface of the wafer giving the C-shape of an individual crack in the line of repetitive cracks. The impurity particle will at a high level of surface loading break free from the torn surface with some debris generated but to move laterally it must now be pushed into the pad surface vertically since the tear protrudes from the wafer surface. With this vertical momentum another bounce back to the wafer surface is initiated. The frequency of bounces can be determined not by the size of the ramp but by the simple physics of a mass (the particle) on a spring (the pad). The governing equation is:

$$
F=k_{1} x=m \frac{d^{2} x}{d t^{2}}
$$

where $\mathrm{k}_{1}$ is the spring constant of the pad, $\mathrm{m}$ is the mass of the particle and $\mathrm{x}$ is the vertical distance that the particle moves into the pad during rebound. The solution to the above equation is given by:

$$
x=A \sin \left(\omega t+\theta_{o}\right)
$$

where $\mathrm{A}$ is the amplitude given by:

$$
\left.A=\sqrt{x_{o}{ }^{2}+\left(v_{o} / \omega\right.}\right)^{2}
$$


where $\mathrm{x}_{\mathrm{o}}$ is the initial displacement of the particle in the pad and $\mathrm{v}_{\mathrm{o}}$ is the initial vertical velocity of the particle. The angular frequency, $\omega$, (and frequency, $f$,) for a mass on a spring are given $\mathrm{by}^{25}$ :

$$
\omega=\frac{2 \pi}{T}=2 \pi f=\sqrt{\frac{k_{1}}{m}}
$$

where $\mathrm{T}$ is the period of oscillation. The spring constant, $\mathrm{k}_{1}$, for a cubic particle with an edge length, 1 , being pushed into a porous pad is approximated $\mathrm{by}^{26}$ :

$$
k_{1} \propto E_{r e l}^{`} l
$$

where $E_{\text {rel }}$ is the relative elastic (Young's) modulus for the contact of the particle and the pad is given by:

$$
E_{r e l}=\left[\frac{1-v_{\text {particle }}^{2}}{E_{\text {particle }}}+\frac{1-v_{\text {pad }}^{2}}{E_{\text {pad }}}\right]^{-1} \text {. }
$$

where $v$ is Poisson's ratio and E is the elastic modulus. Since the particle is a hard material the relative to the pad this equation for the relative elastic modulus can be simplified to ${ }^{27}$ :

$$
E_{r e l}^{\prime} \approx \frac{E_{p a d}}{\left(1-v_{p a d}^{2}\right)}
$$

The period for particle bouncing is given by $1 / 2$ the period of oscillation for a mass on a spring because the particle cannot complete an oscillation without hitting the wafer half way through its cycle. 
Using an assumed $10 \mu \mathrm{m}$ cubic particle with an impurity density of $4 \mathrm{gm} / \mathrm{cc}$, a polyurethane pad with a porosity of $70 \%$ and borosilicate wafer surface, the particle bouncing period is $1 / 2 \times 0.5 \mu \mathrm{s}=0.25 \mu \mathrm{s}$. Assuming that the relative speed of the pad to the wafer during CMP is $1 \mathrm{~m} / \mathrm{s}$ (it can vary from 0.1 to $3.85 \mathrm{~m} / \mathrm{s}$ in practice ${ }^{28},{ }^{29}$ ), the distance between points of surface cracks is $0.25 \mu \mathrm{m}$, which is the correct order of magnitude for what was observed in Figure 13, e.g. $0.33 \mu \mathrm{m}$. This result is encouraging since we did not know either the size of the bouncing indenter particle nor the relative velocity of the pad to the wafer in this example.

In addition, we need to verify that there is sufficient force or load generated to indent the wafer surface when the impurity particle collides with the wafer. Using the governing equation 4 , there is sufficient force when the particle hits the wafer surface to indent the borosilicate glass surface and to open up a radial crack $10 \mathrm{~nm}$ deep assuming an indenter tip on the impurity particle of $100 \mathrm{~nm}$ diameter and a maximum displacement of $50 \mathrm{~nm}$ for the particle above the wafer surface. The depth of the crack observed in Figure 12 is $45 \mathrm{~nm}$. To explain this extra length we must either assume a larger maximum displacement than $50 \mathrm{~nm}$ or add a lateral stress, $\sigma$, to the opening and use equation 5 . When this is done, we can approximate the lateral (or shear) stress to be $5.3 \mathrm{GPa}$ that would be necessary to crack the wafer to a depth of $45 \mathrm{~nm}$. The lateral shear would open up a combination Mode II-Mode III tear in the surface giving the C-shape to this type of crack. 
The total length of the crack from tip to tip of the C-shape observed in Figure 13 is 0.61 $\mu \mathrm{m}$. The observed length and the observed depth $(45 \mathrm{~nm})$ of the chatter cracks shown in Figure 13 can be used to determine the amount of energy required in creating these cracks since the fracture surface energy of borosilicate glass in known to be 45.3 Joule $/ \mathrm{m}^{2}$. The energy required to create one of these individual chatter cracks is $1.2 \times 10^{-12}$ Joule.

In some cases the rebound force can be sufficiently large to imbed the particle into the surface of the wafer, see Figure 14. This most often occurs when the rebound happens over a metal that can undergo plastic deformation and absorb the impact with surface damage. The damage is in the form of a crater that is molded to the particle's shape thereby detaching it from the pad and fixing it into the surface of the wafer.

Finally, it is necessary to get some sense of typical results for surface damage when scratching is prevalent during CMP. The following observations come from Cabot Microelectronics upon characterizing the scratches on thousands of wafers:

ILD wafer surfaces show only one type of surface damage chatter scratches that are referred to as brittle fracture scratches in this report.

Copper wafer surfaces show:

1) Irregular pattern skipping scratches corresponding to $60 \%-80 \%$ of total. 
2) Line scratches also called razor scratches or plastic plow scratches in this document corresponding to $5-25 \%$ of the total except in the case of some Ta polishing colloidal $\mathrm{SiO}_{2}$ slurry formulations with a hard pad when line scratches are the dominant mode of surface damage.

3) Rolling particle surface damage corresponding to $0-20 \%$ of the total.

These observations are consistent with what would be predicted for the scratching of a brittle material like silicate produced by plasma enhanced chemical vapor deposition of tetra ethyl orthro silicate (PETEOS). Since the material is elastic up to the point of rupture as shown in Figure 1b, PETEOS should not show any indenter marks since this material is brittle it can not fail by plastic deformation. PETEOS, however, can and does fail by brittle fracture. These observations are also consistent with what would be predicted for the scratching of a ductile material, copper, as the material is plastic for most of its deformation range after an initial elastic limit is reached at a very small amount of deformation as is shown Figure 1a. As polycrystalline copper is highly plastic up to a strain (or elongation) of 53\% it is nearly impossible to cause it to undergo brittle fracture and rupture in CMP.

\section{Conclusions}

Hard impurity particles present in the CMP slurry are responsible for surface damage in both ductile (e.g. copper) and brittle (e.g. ILD) materials at the wafer surface. The shapes of the ILD surface damage consistently show only brittle fracture failure. When the load is sufficiently high, lateral cracks are formed which form chips that become debris 
particles that are swept away from the wafer surface and into the CMP slurry potentially causing further surface damage. Surface damage in copper is plastic plow damage and rolling particle indenter damage, typical of a ductile material. Examples of both of these surface damage mechanisms, including several variances unique to CMP are shown in this paper and explained in terms of fracture mechanics and impurity particle dynamics. 
Figures Legends

(to be printed in black and white or grey scale)

Figure 1a, Normal Stress Strain curve for Copper showing the yield stress that occurs after the elastic region, the plastic zone, the tensile strength and elongation at rupture. The Young's modulus for copper is $110 \mathrm{GPa}$. Data for this figure taken from "The Physics of Solids," by Richard Turton. Figure 1b) Normal Stress Strain curve for Borosilicate Glass showing that there is only a linear (elastic) region up to the tensile strength. The Young's modulus for BSG is $62 \mathrm{GPa}$.

Figure 2, Surface Fracture Modes

Figure 3, Normal Stress Distribution under a spherical indenter ${ }^{30}$. The surface of the indenter is deformed so that it makes contact with the flat surface. The normal stress is given in the contours as the stress, $\sigma / \mathrm{P}_{\mathrm{o}}$, where $\mathrm{P}_{\mathrm{o}}$ is the applied pressure acting on the spherical indenter.

Figure 4, Schematic of a semi-circular indentation crack of length $\mathrm{c}$ under the action of residual and applied tensile stress, $\sigma$.

Figure 5, Surface (a) and subsurface (b) structure of a Vicker's indentation crack. The radial cracks protrude to the surface and are observed in (a) at 4 locations. The lateral cracks are observed in (a) as the grey zone surrounding the indenter's depression. The 
surface of a copper pattern with rolling indenter (c) surface damage. In Figure $5 \mathrm{C}$, the bar equals $10 \mu \mathrm{m}$.

Figure 6a \& b, Schematic of Plastic Deformation (left panel, showing erosion debris with material plowed up on the wafer surface) and Brittle Fracture (right panel, showing lateral cracks which will flake off if they protrude to the wafer surface). In Figure 6a and $6 \mathrm{~b}$ micrographs, the bar is $1 \mu \mathrm{m}$.

Figure 7, Size Distribution of Scratches Produced in ILD (A) and Copper (B) by Impurity Particles of Various Sizes; solid line $=1$ microns, dotted line $=2$ microns, $\underline{\text { dashed line }=4}$ microns, dot-dash line $=8$ microns. Note, load magnification due to the hardness of the impurity particle is not taken into account in this plot.

Figure 8, Elastic/plastic contact damage. Shading represents plastic zone. Extending from the plastic zone in all directions are lateral cracks, which due to stress in the surface delaminate as shown on the right of the figure.

Figure 9, Examples of Surface Damage of Metalization Layers. a) \& b) are examples of plastic deformation surface damage showing V-shaped scratches in a patterned copper wafer surface. The width of the scratch in the copper is $160 \mathrm{~nm}$ in $\mathrm{b}$ ). In some cases the scratch occurs in both the copper and tantalum metal surfaces with different depths as in c. Multiple scratches from a single impurity particle causes multiple-parallel scratches as in d) e) and f) are meandering surface damage marks in copper. Figure $9 g$ ) and h) are 
examples of brittle fracture surface damage in borosilicate glass. Photos are from Cabot Microelectronics.

Figure 10, Rolling Particle surface damage, where sharp edges associated with the elongated axis of the particle act as indenters. Arrow indicates the direction of rolling particle. Photo from Cabot Microelectronics. Bar $=10 \mu \mathrm{m}$.

Figure 11, Width and length distribution of surface damage traces made by rolling indenter particles in copper CMP. Results for Lognormal fits shown as the blue lines with a) Geometric Mean Repeat Spacing $=10.85 \mu \mathrm{m}, \sigma_{\mathrm{g}}=1.997$, b) Geometric Mean Width $3.52 \mu \mathrm{m}, \sigma_{\mathrm{g}}=1.90$, upon analysis of 75 surface defects of this type.

Figure 12, Chatter Surface Damage Showing the Repetitive $40 \mathrm{~nm}$ Deep Indentations in the Copper Wafer Surface.

Figure 13, Sectional Analysis of Chatter Surface Damage Shown in Figure 12.

Figure 14, Hard Impurity Particle Imbedded in Copper Pattern (a) of Wafer Surface after CMP with EDAX (b) of Particle Showing $\mathrm{Cu}, \mathrm{SiO}_{2}$ and a Trace of $\mathrm{Al}_{2} \mathrm{O}_{3}$. 


\section{Appendix A - Mechanical Properties of Materials}

Table A.1 collects the mechanical properties of the materials that are important in CMP.

Table A.1 Mechanical Properties of IC Materials encountered in CMP Process ${ }^{31}$

\begin{tabular}{|c|c|c|c|c|c|c|c|}
\hline Material & $\begin{array}{l}\text { Molecular } \\
\text { Weight } \\
\text { gm/mole }\end{array}$ & $\begin{array}{l}\text { Density } \\
\text { gm } / \mathrm{cm}^{3}\end{array}$ & $\begin{array}{l}\text { Poisson's } \\
\text { Ratio, } \\
\text { v }\end{array}$ & $\begin{array}{l}\text { Knoop } \\
\text { Hardness, } \\
\text { H } \\
\text { GPa }\end{array}$ & $\begin{array}{l}\text { Modulus at } \\
\text { Rupture or } \\
\text { Tensile } \\
\text { Strength, } \\
\text { MPa }\end{array}$ & $\begin{array}{l}\text { Young's } \\
\text { Modulus, } \\
\text { E } \\
\text { GPa }\end{array}$ & $\begin{array}{l}\text { Fracture } \\
\text { Toughness, } \\
\mathrm{K}_{\mathrm{c}} \\
\mathrm{MPa} \mathrm{m}^{1 / 2}\end{array}$ \\
\hline $\mathrm{Si}$ & 28.086 & 2.329 & & 1 & & 98.74 & 0.6 \\
\hline
\end{tabular}

Metals that form the wires and vias

\begin{tabular}{|l|l|l|l|l|l|l|l|}
\hline Mo & 95.94 & 10.22 & & - & & 278 & $10-100 ?$ \\
\hline W & 183.84 & 19.3 & 0.28 & $3-3.4$ & & 398 & 20 \\
\hline $\mathrm{Cu}$ & 63.546 & 8.96 & 0.34 & $(0.874$, & 220 & 130 & $50-100$ \\
\hline $\mathrm{Al}$ & 26.982 & 2.71 & 0.33 & 1.4 & 55 & 72 & $35-45$ \\
\hline $\mathrm{Ag}$ & 107.87 & 10.49 & 0.37 & & 125 & 76 & \\
\hline Ta & 180.95 & 16.69 & 0.34 & $(0.873$, & & 186 & \\
\hline Ti & 47.86 & 4.51 & 0.32 & $(0.97$, & 330 & 116 & $30-100 ?$ \\
& & & & Vickers $)$ & & & \\
\hline
\end{tabular}


Oxides, Dielectrics, and CMP Abrasives

\begin{tabular}{|l|l|l|l|l|l|l|l|}
\hline $\mathrm{NO}_{3}$ & 231.84 & 7.2 & & & & $100-300 ?$ & $3-10 ?$ \\
\hline $\mathrm{Cu}_{2} \mathrm{O}$ & 143.09 & 6.0 & & 1.7 & & $100-300 ?$ & $3-10 ?$ \\
\hline $\mathrm{CuO}$ & 79.545 & 6.3 & & 1.5 & & $100-300 ?$ & $3-10 ?$ \\
\hline $\mathrm{Al}_{2} \mathrm{O}_{3}$ & 101.96 & 3.97 & 0.27 & 21 & $275-550$ & 393 & $3.5-4.5$ \\
\hline $\mathrm{TiO}_{2}$ & 79.90 & 4.04 & & $6-10$ & & $100-300 ?$ & $3-10 ?$ \\
& $\begin{array}{l}\text { Anatase } \\
4.26\end{array}$ & & & $8-10$ & & $100-300 ?$ & $3-10 ?$ \\
\hline $\mathrm{Fe}_{3} \mathrm{O}_{4}$ & 231.54 & 5.20 & & $6-10$ & & $100-300 ?$ & $3-10 ?$ \\
\hline $\mathrm{Fe}_{2} \mathrm{O}_{3}$ & 159.69 & 5.26 & & $4-8$ & & & \\
\hline $\mathrm{ZrO}_{2}$ & 123.22 & 5.68 & 0.32 & 12 & $138-240$ & 138 & 8.4 \\
\hline $\mathrm{SiO}_{2}$ & 60.085 & 2.2 & 0.16 & 5.5 & 110 & 72 & $0.7-0.9$ \\
\hline $\mathrm{BSG}^{2}$ & - & 2.23 & 0.20 & $3-5$ & 69 & 69 & 2.5 \\
\hline
\end{tabular}


Table A.1 Continued

Polish Stop materials and other Hard IC Materials

\begin{tabular}{|c|c|c|c|c|c|c|c|}
\hline Material & $\begin{array}{l}\text { Mole } \\
\text { Weight }\end{array}$ & Density & $\begin{array}{l}\text { Poisson's } \\
\text { Ratio, v }\end{array}$ & $\begin{array}{l}\text { Knoop } \\
\text { Hardness, } \\
\text { H } \\
\text { GPa }\end{array}$ & $\begin{array}{l}\text { Modulus at } \\
\text { Rupture or } \\
\text { Tensile } \\
\text { Strength, } \\
\text { MPa }\end{array}$ & $\begin{array}{l}\text { Young's } \\
\text { Modulus } \\
\text {,E } \\
\text { GPa }\end{array}$ & $\begin{array}{l}\text { Fracture } \\
\text { Toughness } \\
\text { K }_{\mathbf{c}} \\
\text { Mpa m }^{1 / 2}\end{array}$ \\
\hline $\mathrm{SiC}$ & 40.10 & 3.22 & 0.19 & 25 & $450-520$ & 414 & $3-5 ?$ \\
\hline $\mathrm{Si}_{3} \mathrm{~N}_{4}$ & 140.28 & 3.17 & 0.24 & 22 & $414-580$ & 304 & $5.6-11$ \\
\hline $\mathrm{BN}$ & 24.82 & 2.27 & & 20.5 & & 83 & - \\
\hline $\mathrm{TiC}$ & 59.91 & 4.93 & & 26 & & 462 & - \\
\hline TiN & 61.91 & 5.22 & & & & & \\
\hline AlN & 40.989 & 3.26 & & 12 & & 331 & $3-7 ?$ \\
\hline $\mathrm{WC}$ & 195.86 & 15.63 & & & & $450-650$ & - \\
\hline $\begin{array}{l}\text { Diamond } \\
\end{array}$ & 12.011 & 3.51 & & $78-100$ & & 1035 & $2.5 ?$ \\
\hline
\end{tabular}

Pad Materials and Polymers

\begin{tabular}{|l|l|l|l|l|l|l|l|}
\hline Polyurethane & - & $\sim 1$ & 0.25 & $5-10 ?$ & & $0.2 ?$ & $1-3 ?$ \\
\hline Polymer & - & 0.96 & & $5-10 ?$ & $8.3-31$ & 0.172 & $1-3 ?$ \\
DPE & & & & & & & \\
\hline
\end{tabular}




\section{References}

${ }^{1}$ Sundararajan, S., Thakurta, D.G., Schwendeman, D.W., Murarka, S.P. and Gill, W.N.,” Two-Dimensional Wafer-Scale Chemical Mechanical Planarization Models Based on Lubrication Theory and Mass Transport," J. Electrochemical Soc. 146(2), 761-66(1999).

${ }^{2}$ Subramanian, R.S., Zhang, L. and Babu, S.V., "Transport Phenomena in Chemical Mechanical Polishing,” J. Electrochemical Soc. 146(11),4263-72,(1999).

${ }^{3}$ Vlassak, J.J., Mat. Res. Sco. Symp. Proc. Vol. 671,M4.6.1-6, 2000

${ }^{4}$ Ahmadi,G. and Xia, X., J. Electrochemical Soc. 148(3),G99-G109(2001).

${ }^{5}$ Vlassak, J.J., Mat. Res. Soc. Symp. Proc. Vol 671,p. M4.6.1-6,(2001)

${ }^{6}$ Remsen, E.E., Anjur, S. P., Boldridge, D., Kamiti, M., Li, S., Johns, T. Dowell, C., Kasthurirangan, J. and Feeney, P., "Correlation of Defects on Dielectric Surfaces with Large Particle Counts in CMP Slurries Using a New Single Particle Optical Sensing (SPOS) Technique,” J. Electrochemical Soc. 153(5),G453G461 (2006).

7 "Linear Fracture Mechanics: Historical Developments and Applications of Linear Fractur Mechanics Theory," G.C. Sih, R.P. Wei and F. Erdogan, editors, Lehigh University, Envo Pub. Co., 1975, p. xii-xvi. ${ }^{8}$ Bell, T.J., Field, J.S., Lesha, J. F. and Swain, M.V., "Evaluation of the effective radius of spherical indenters for ultra-microindentation,” MRS Symp. Proc. Vol. 522, p. 15-20, 1998.

${ }^{9}$ Green, D.J., "An Introduction to the Mechanical Properties of Ceramics," Cambridge University Press, 1998, p.243.

${ }^{10}$ ibid, p. 243, equation 8.63 .

${ }^{11}$ Evans, A.G. and Marshall, D.B. "Wear Mechanisms in Ceramics," in Fundamentals of Friction and Wear of Materials," edited by David A. Rigney, American Society for Metals., Metals Park, Ohio, 1981, p. $439-441$.

${ }^{12}$ Moore, M.A., "Abrasive Wear," in Fundamentals of Friction and Wear of Materials," edited by David A. Rigney, American Society for Metals., Metals Park, Ohio, 1981, p. 73-118. 
${ }^{13}$ Evans, A.G. and Marshall, D.B. "Wear Mechanisms in Ceramics," in Fundamentals of Friction and Wear of Materials," edited by David A. Rigney, American Society for Metals., Metals Park, Ohio, 1981, p. 441.

${ }^{14}$ Marshall, D.B.,’Surface Damage in Ceramics: Implications fro Strength Degradation, Erosion and Wear," in Progress in Nitrogen Ceramics, F.L. Riley Editor, Kluwer, New York , 1983, p. 635-656.

${ }^{15}$ Evans, A.G. and Marshall, D.B. "Wear Mechanisms in Ceramics," in Fundamentals of Friction and Wear of Materials," edited by David A. Rigney, American Society for Metals., Metals Park, Ohio, 1981, p. $439-452$.

${ }^{16}$ Marshall, D.B., "Surface Damage in Ceramics: Implications for Strength Degradation, Erosion and Wear," in Progress in Nitrogen Ceramics, F.L. Riley, Ed. Martinus Nijhoff Publishers, (a member of Kluwer Academic), Boston, 1983, p.640.

${ }^{17}$ ibid, p. 640 .

18 ibid. p. 642.

${ }^{19}$ Green, D. J., An Introduction to Mechanical Properties of Ceramics, Cambridge University Press, Cambridge, 1998, p. 244.

${ }^{20}$ Evans, A.G. and Marshall, D.B., in "Fundamentals of Friction and Wear of Materials" p. 441, eq. 1, 7 and 12.

${ }^{21}$ Greenwood, J.A., J. Lubrication Techn. Jan., 1967, p. 81-91.

${ }^{22}$ Greenwood, J.A. and Williamson, J.B., Proc. Royal Soc. A, 295,300-19(1966).

${ }^{23}$ Yu, T-K, Yu, C C. and Orlowski, M., "A Statistical Polishing Pad Model for CMP," Transactions of the International Electron Devices Meeting (1993, Washington, DC), IEEE, 1993, p. 865-868.

${ }^{24}$ Marshall, D.B., "Surface damage in ceramics: Implications for strength degradation, erosion and wear", in Progress in Nitrogen Ceramics edited by F.L. Riley,p. 635-656, Martinus Nijhoff Publishers, Boston, 1983.

${ }^{25}$ Sears, F.W. and Zemansky, M.W., "University Physics, $3^{\text {rd }}$ Ed. Part I, “Addison Wesley, Reading MA, 1963, p.262.

${ }^{26}$ derived from the elastic properties of the pad and particle. 
${ }^{27}$ The pad is often porous and the Elastic modulus is given by $E_{\text {pad }}=E_{o}\left(1-\varepsilon_{\text {pad }}^{2}\right)$ and Poisson's ratio for the pad is given by $v_{p a d}=v_{o}\left(1-\varepsilon_{p a d}^{2}\right)$ where $\varepsilon_{\text {pad }}$ is the pad porosity. [Gibson, L.J. and Ashby, M.F.,"Cellular Solids: Structure and Properties" Oxford University Press (1988)].

${ }^{28}$ Patrick, W.J., Guthrie, W.L., Standley, C.L. and Schiable, P.M. , “Application of Chemical Mechanical Polishing to the Fabrication of VLSI Circuit Interconnects", J. Electrochem. Soc. 138(6)June 1991, p.1778, ${ }^{29}$ Steigerwald, J.M., Murarka, S.P. and Gutmann, R.J., Chemical Mechanical Planarization of Microelectronic Materials,” Wiley-Interscience, New York 1997.

${ }^{30}$ Governing equations from Johnson, K.L., "Contact Mechanics,” Cambridge University Press, 1985, p. 90.

${ }^{31}$ Data from various sources including $7^{\text {th }}$ Edition Dana's System of Mineralogy, Vol. 1, C. Planche, H Berman and C. Frandel, J Wiley, NY, 1944, Sengupta, S., "Lattice Theory of Elastic Constants," Trans Tech Publications Ltd. Switzerland, 1993. and Callister, W.D., Materials Science and Engineering - An Introduciton,” $3^{\text {rd }}$ ed., Wiley, NY, 1994, Evans, A.G. and Marshall, D.B. "Wear Mechanisms in Ceramics," in Fundamentals of Friction and Wear of Materials, ” edited by David A. Rigney, American Society for Metals., Metals Park, Ohio, 1981, p. 439-441. The ? indicate the values are from Ashby, M.F., "Materials Selection in Mechanical Design” Pergamon Press, Oxford, 1979, p.36. 


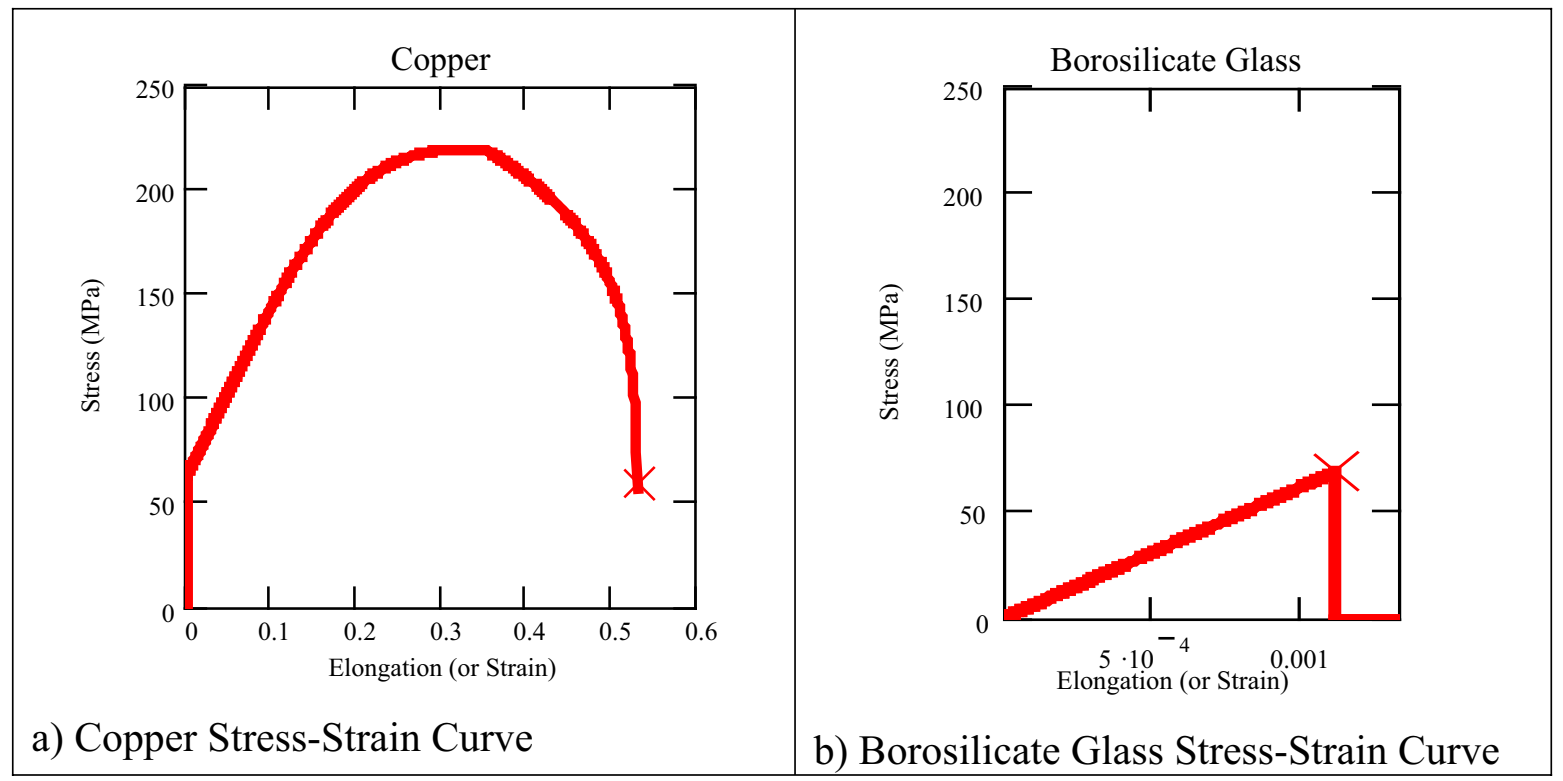



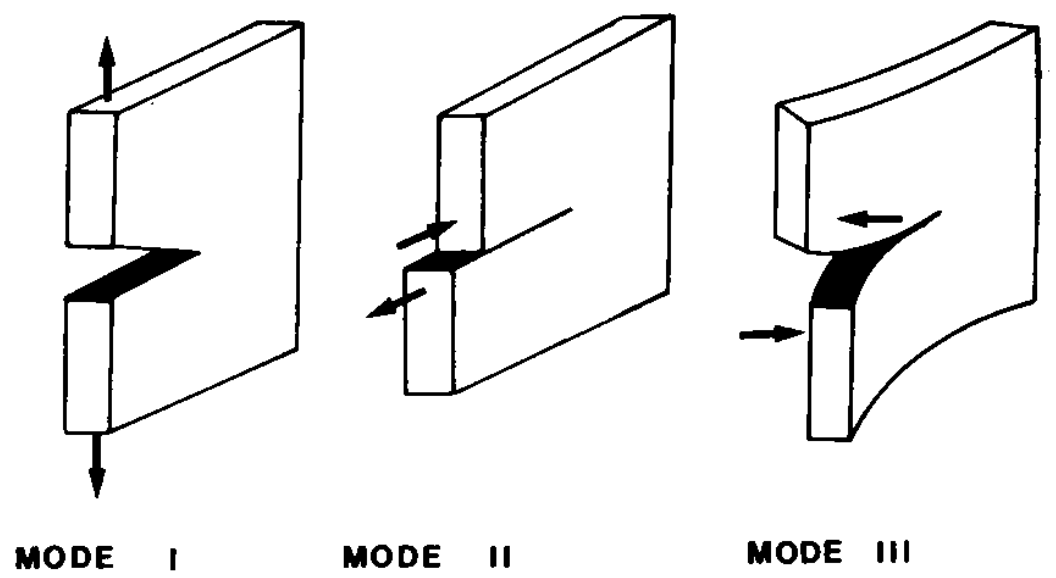


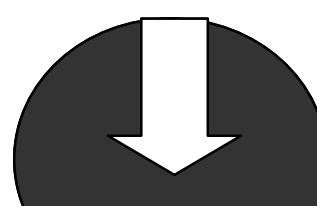

Hertzian Stress, sigma/Po

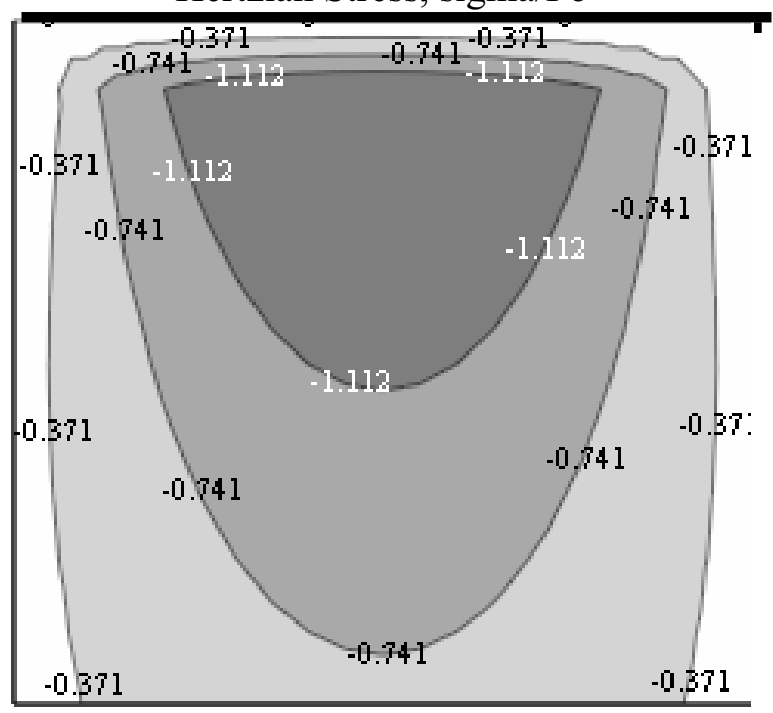




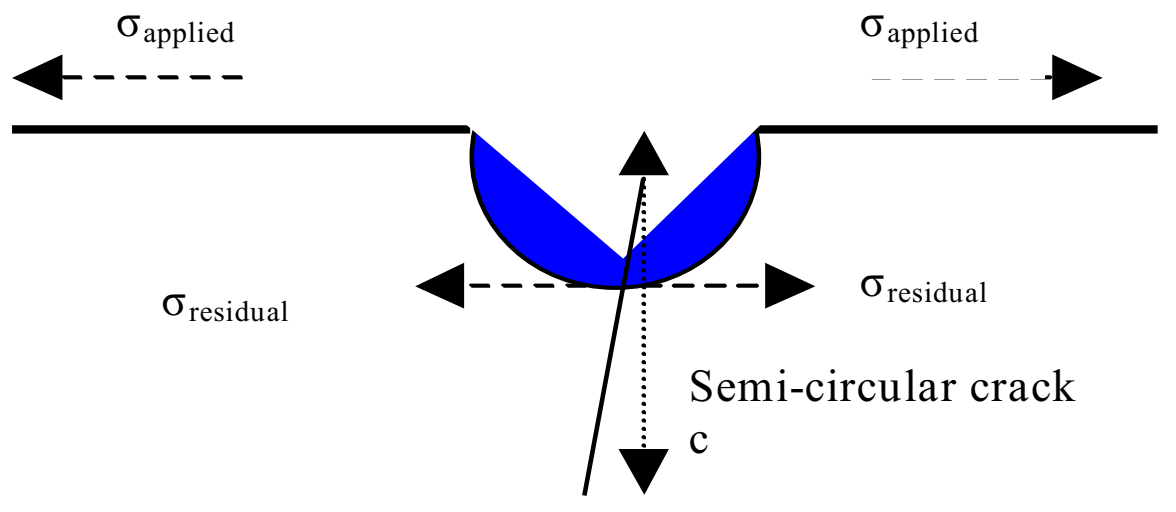




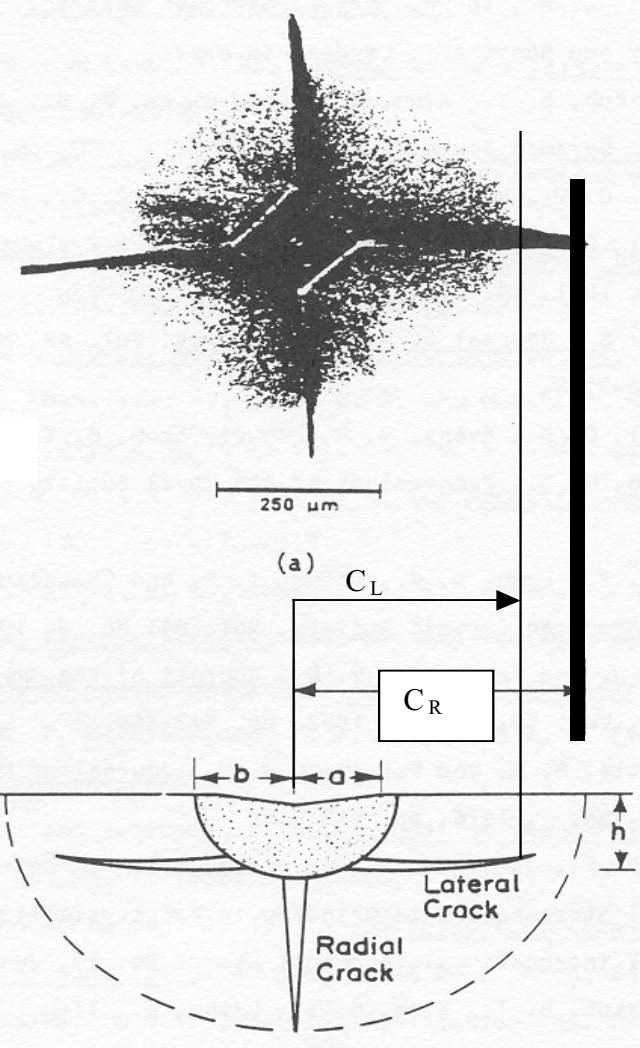

(b)

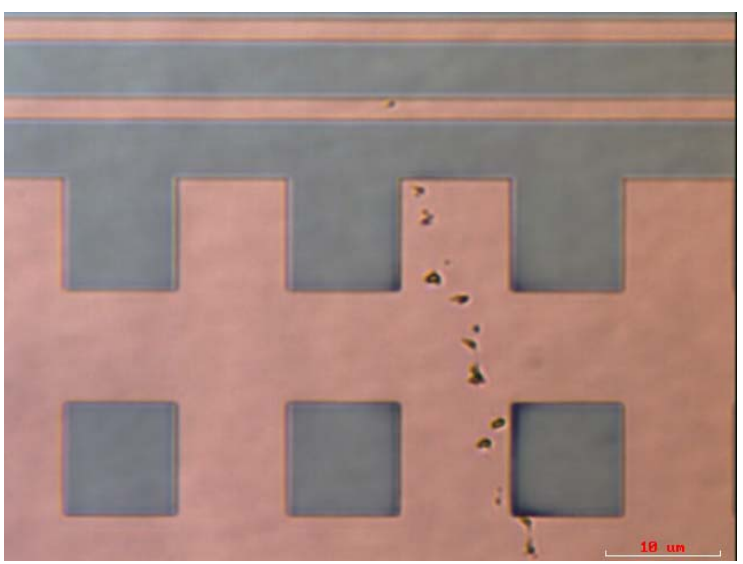

(c) 


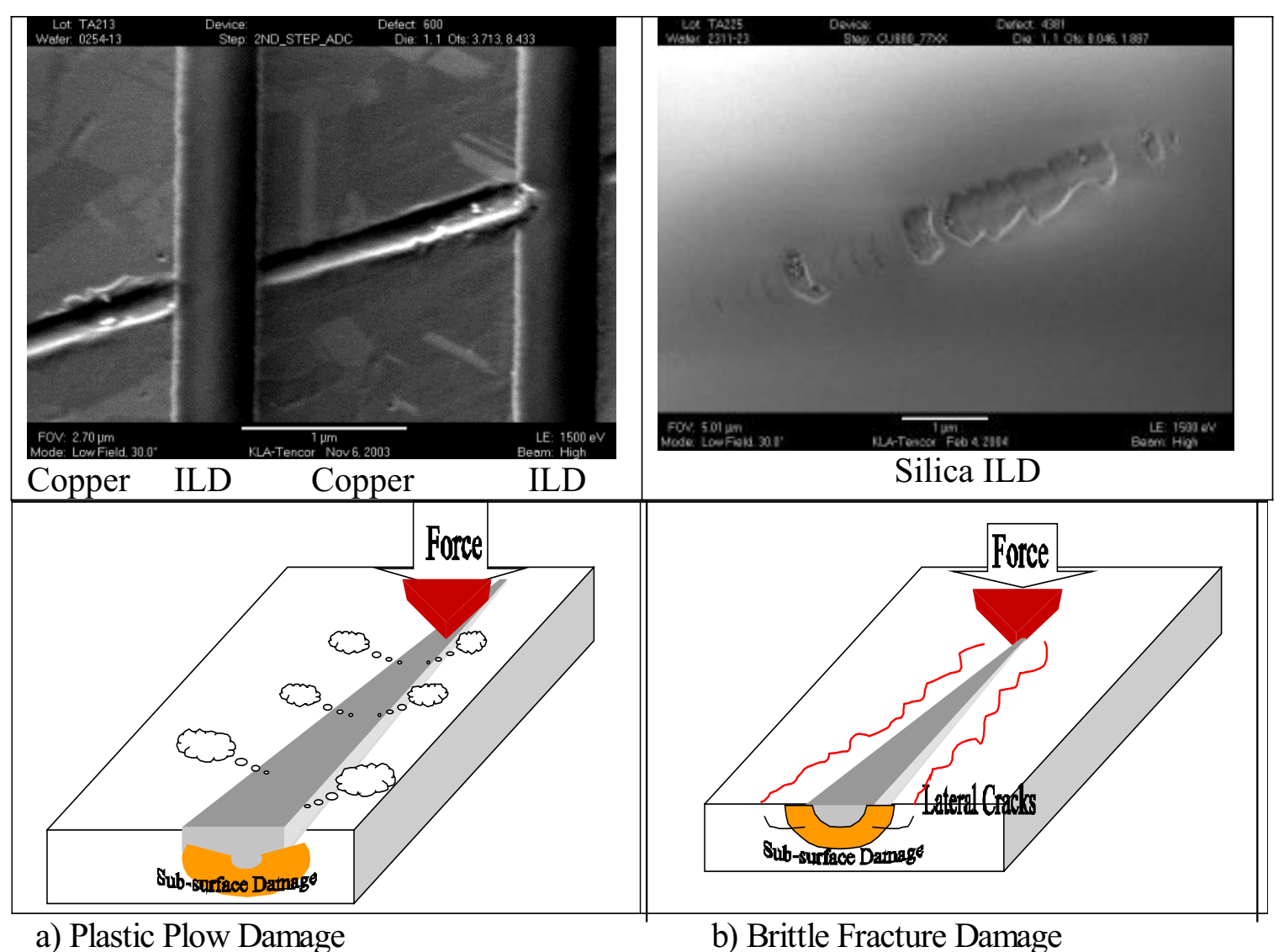

a) Plastic Plow Damage

b) Brittle Fracture Damage 


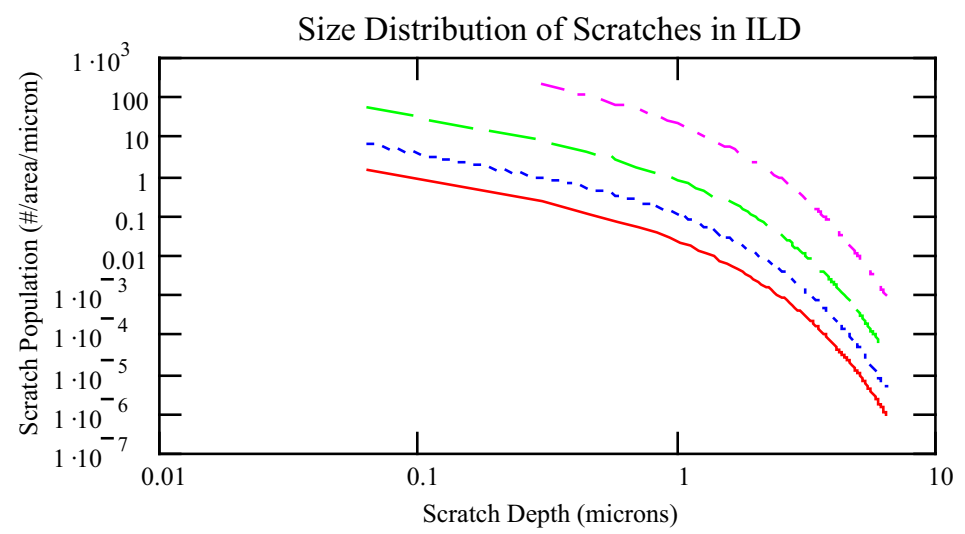

(A)

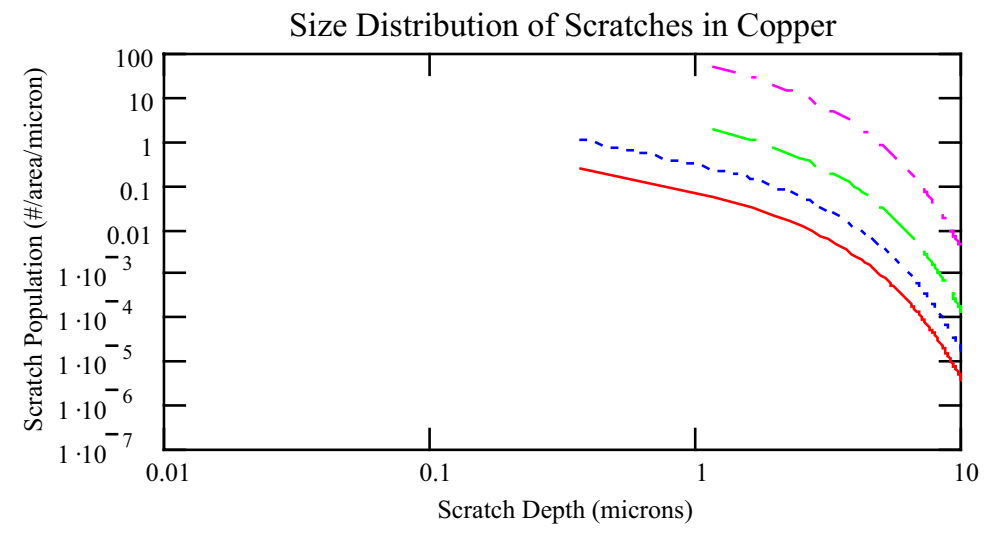

(B) 


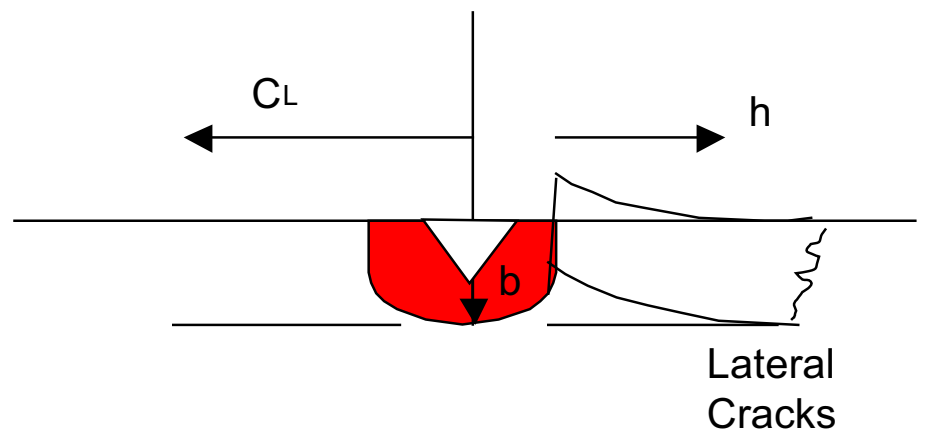




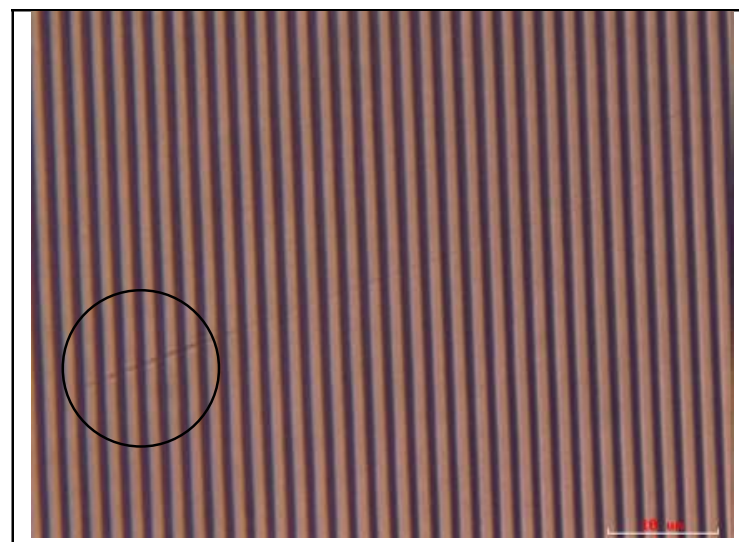

a) Microscope image of line or razor scratche in copper lines, $\mathrm{Bar}=10 \mu \mathrm{m}$.

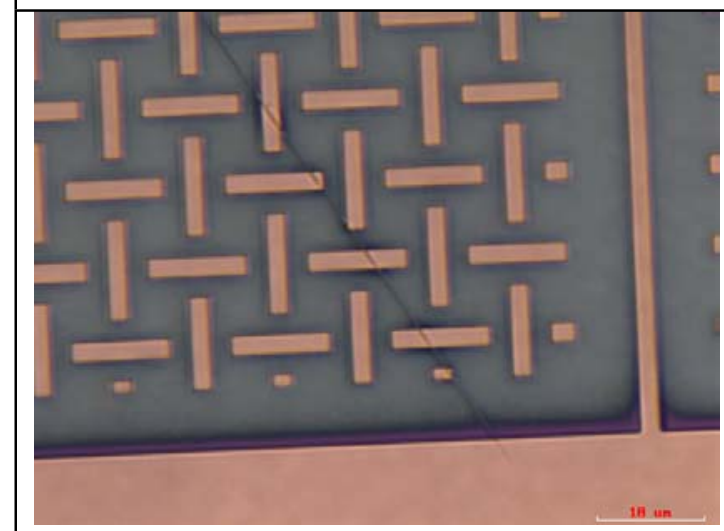

c) Microscope image of copper and tantalum surface damage, Bar $=10 \mu \mathrm{m}$.

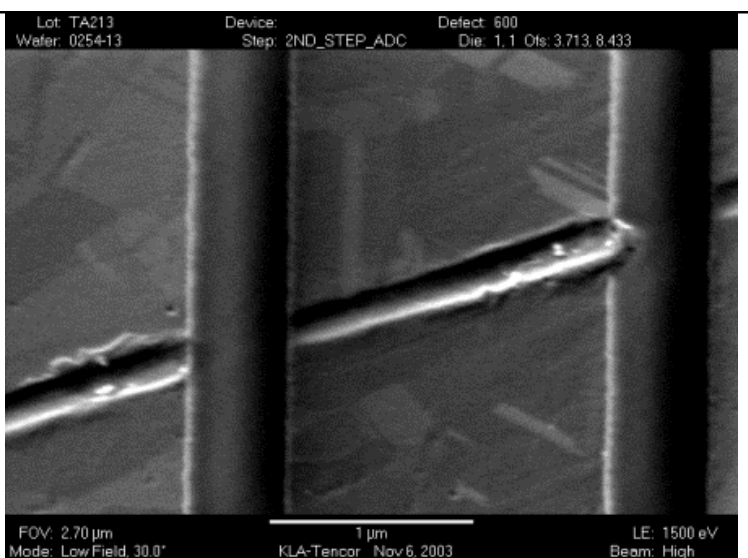

b) SEM image of line scratch in copper lines shown in (a) skipping over BSG spacers along the indenter's trajectory, $\mathrm{Bar}=1 \mu \mathrm{m}$.

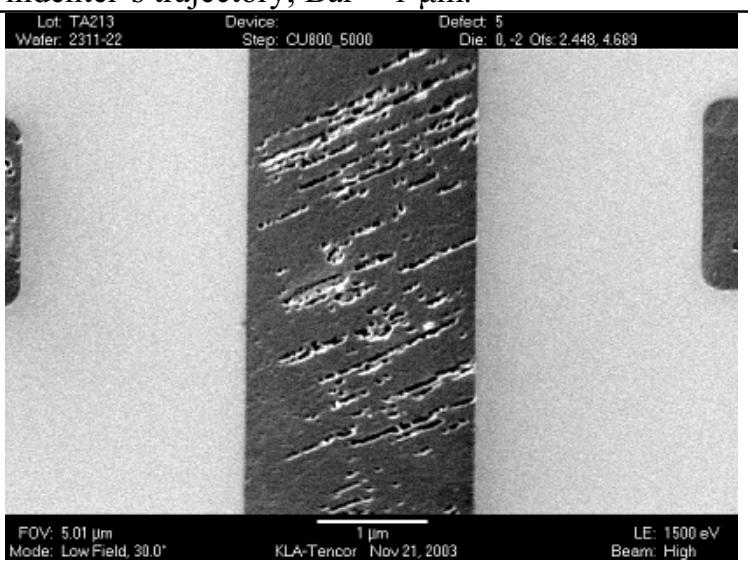

d) SEM image of copper surface damage. Bar $=1 \mu \mathrm{m}$.

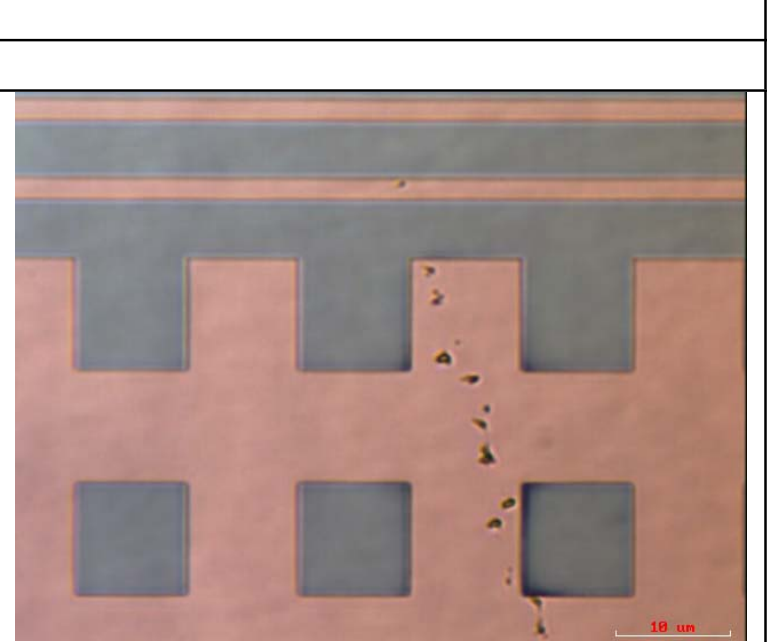

e) Microscope image of copper surface damage, $\mathrm{Bar}=10 \mu \mathrm{m}$.

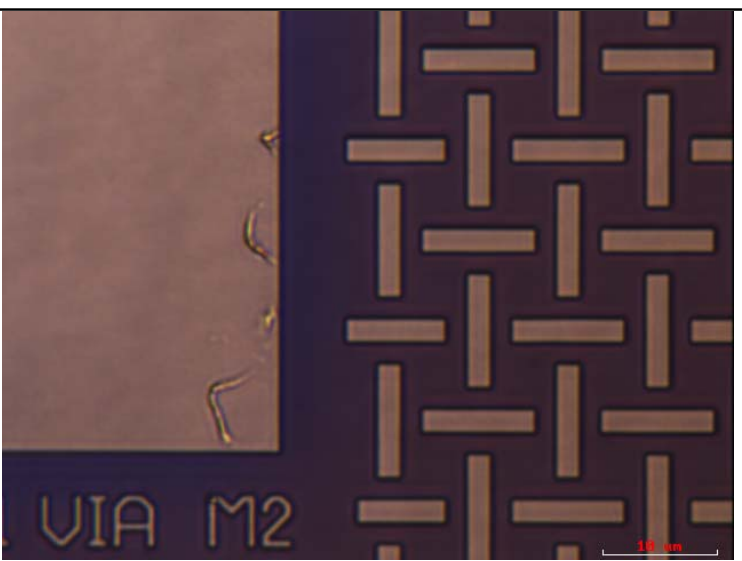

f) Microscope image of copper surface damage, $\operatorname{Bar}=10 \mu \mathrm{m}$. 


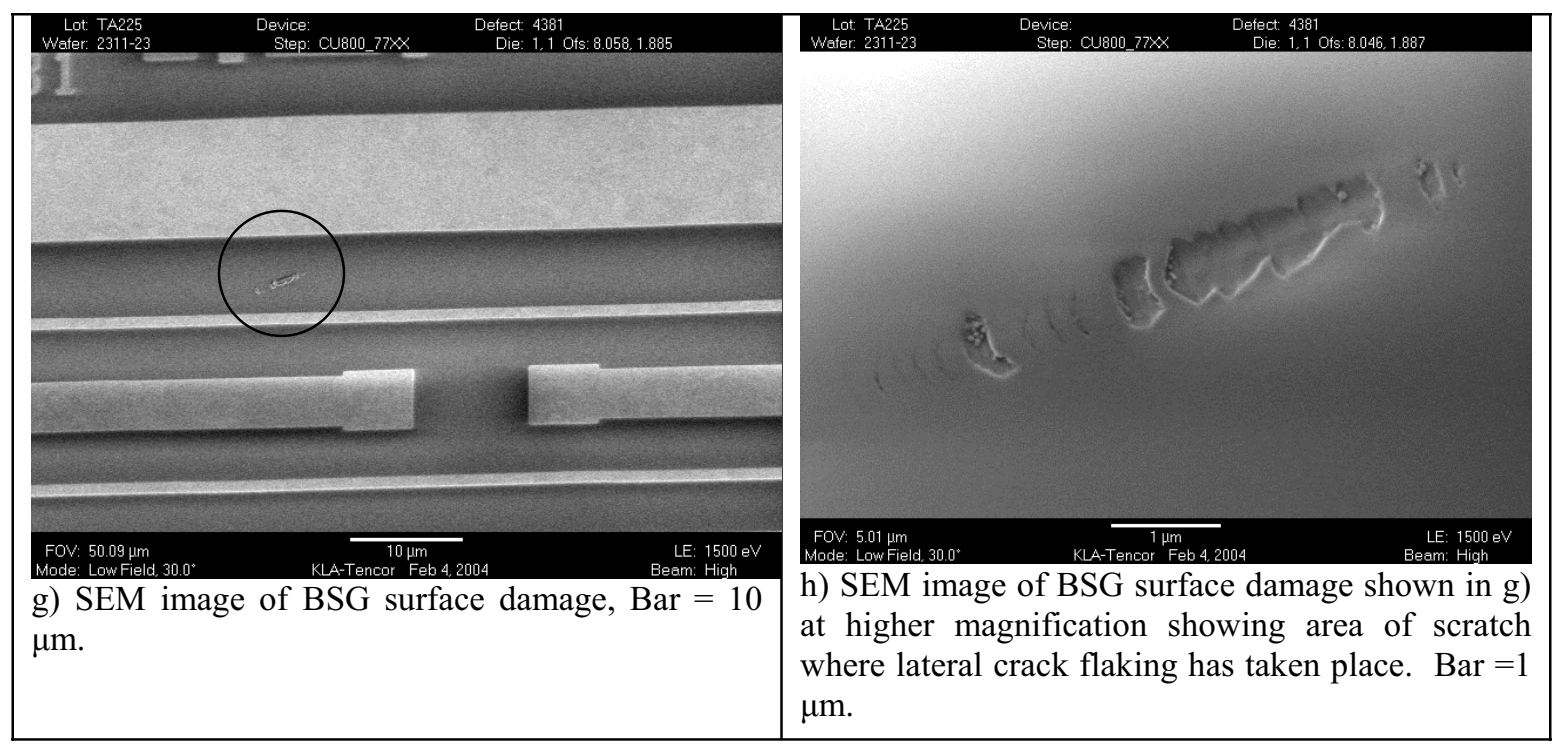




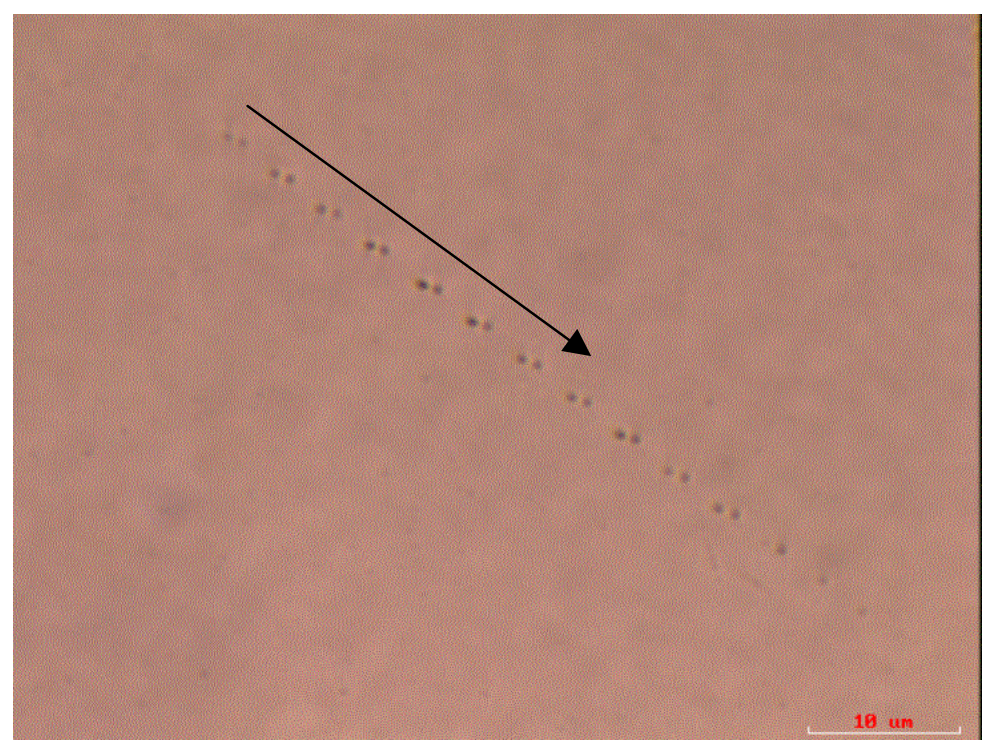




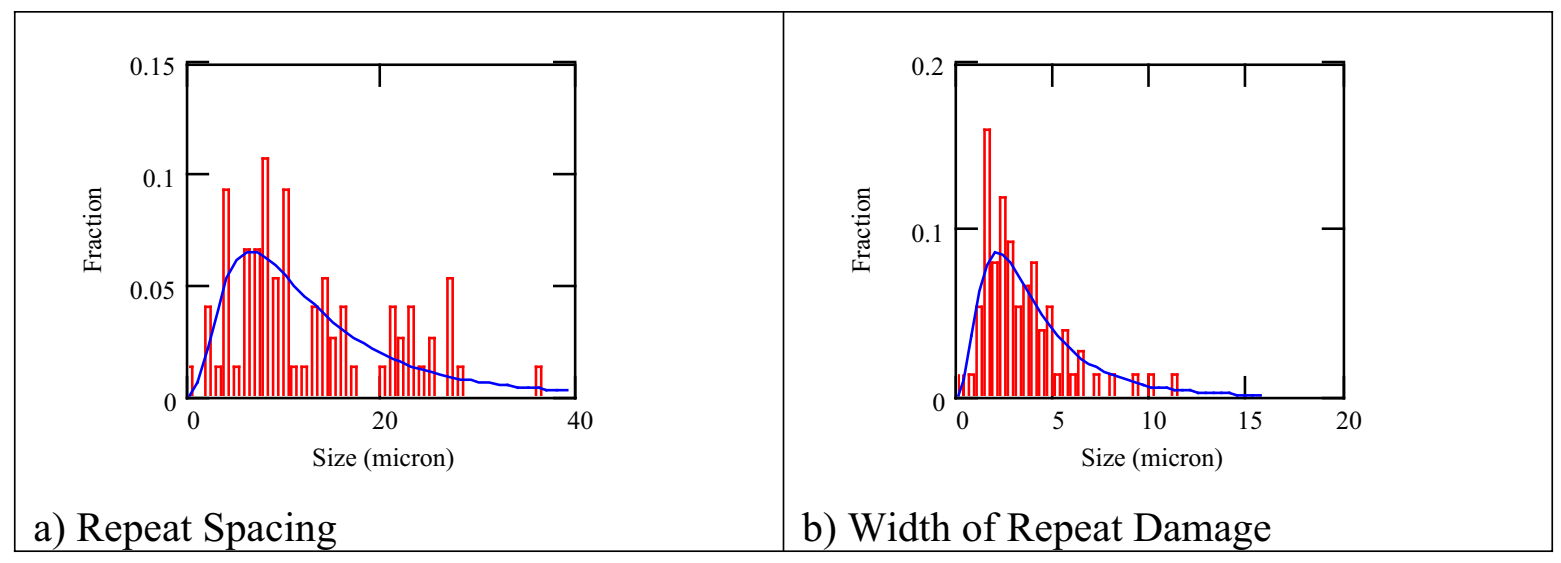




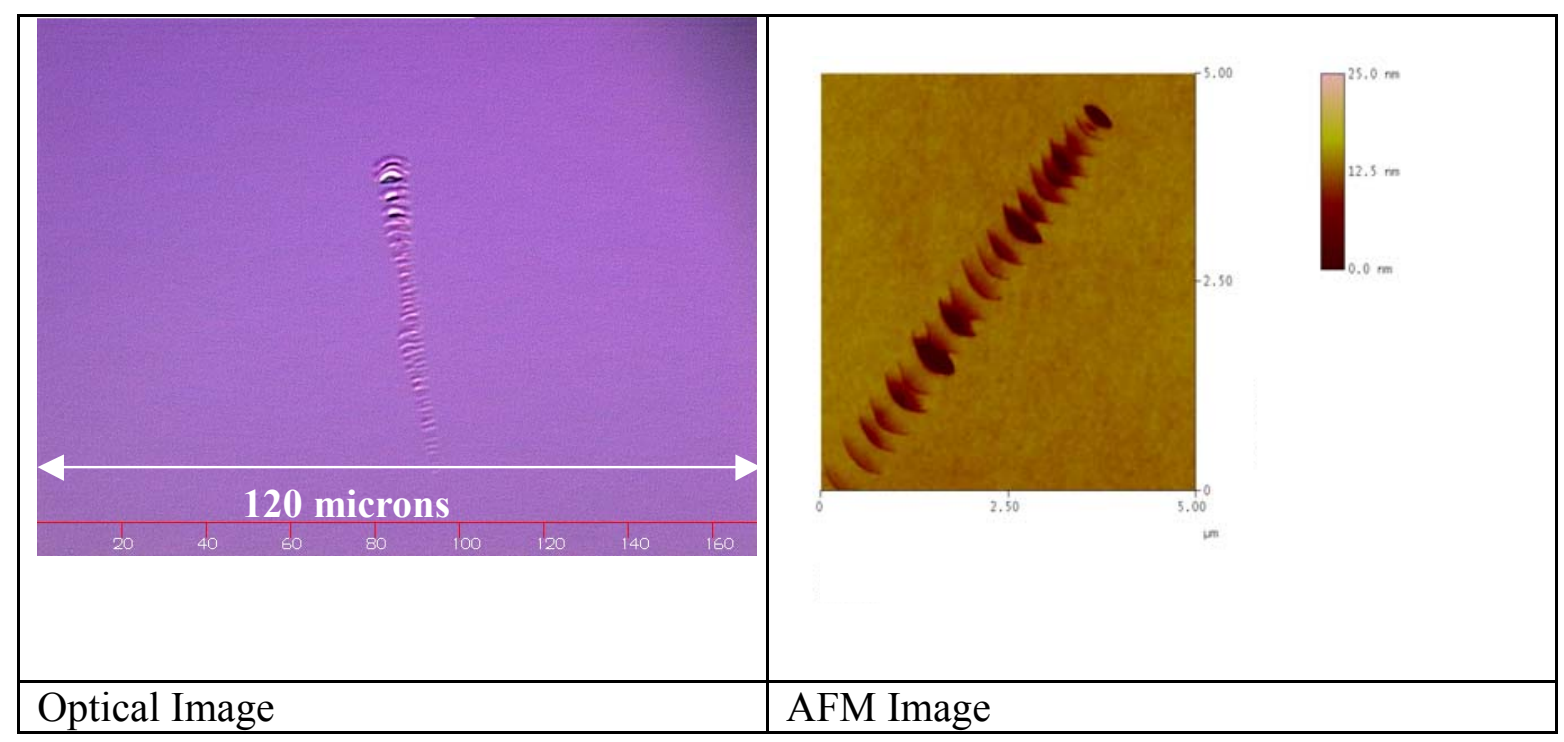


Distance

(nm)

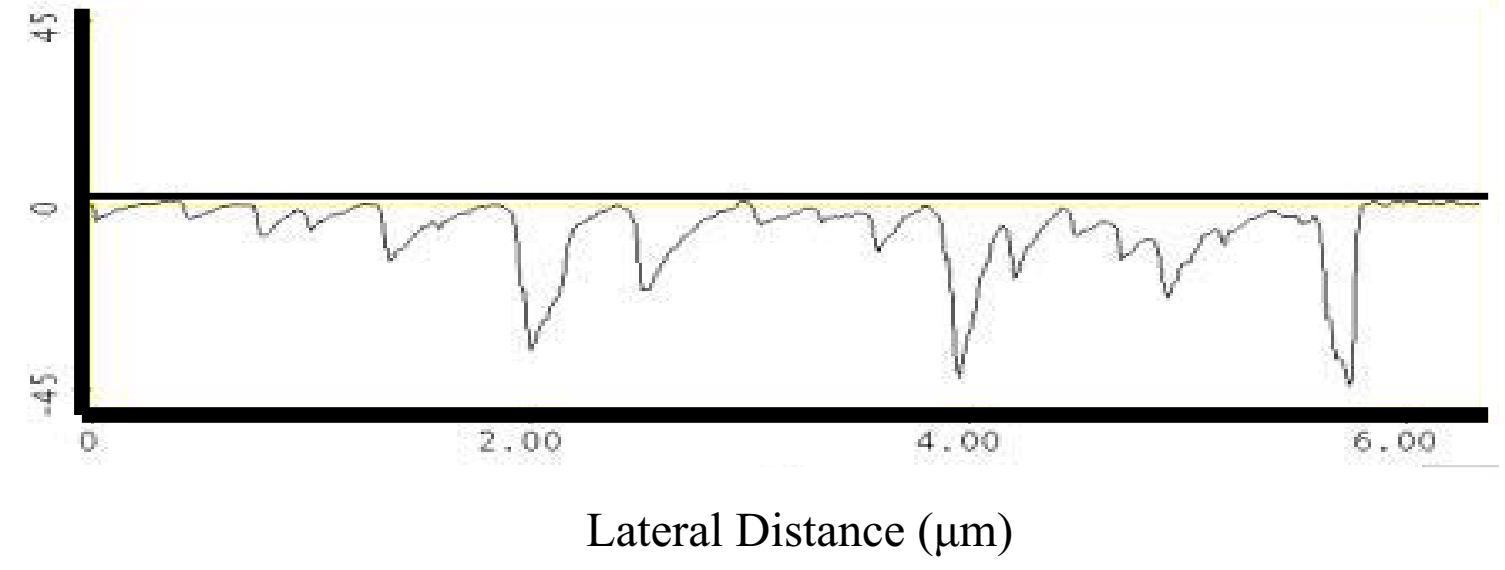




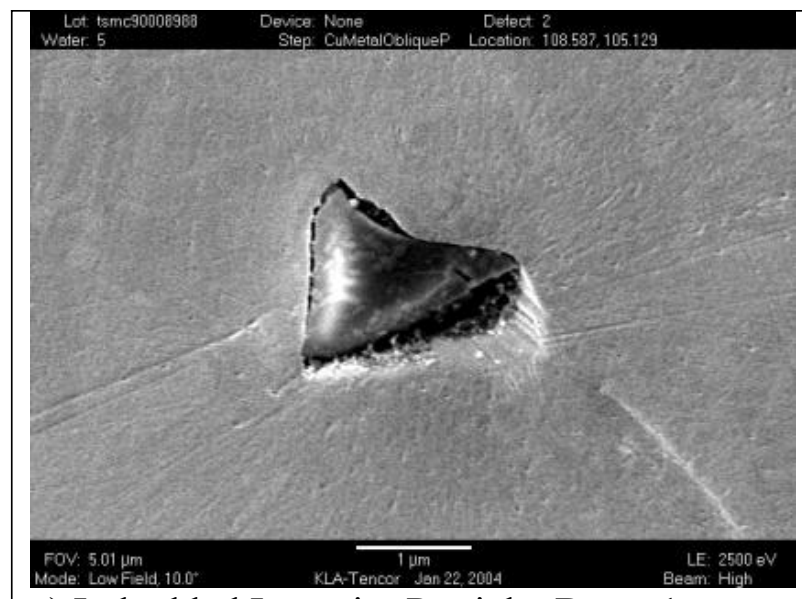

a) Imbedded Impurity Particle, Bar $=1 \mu \mathrm{m}$.

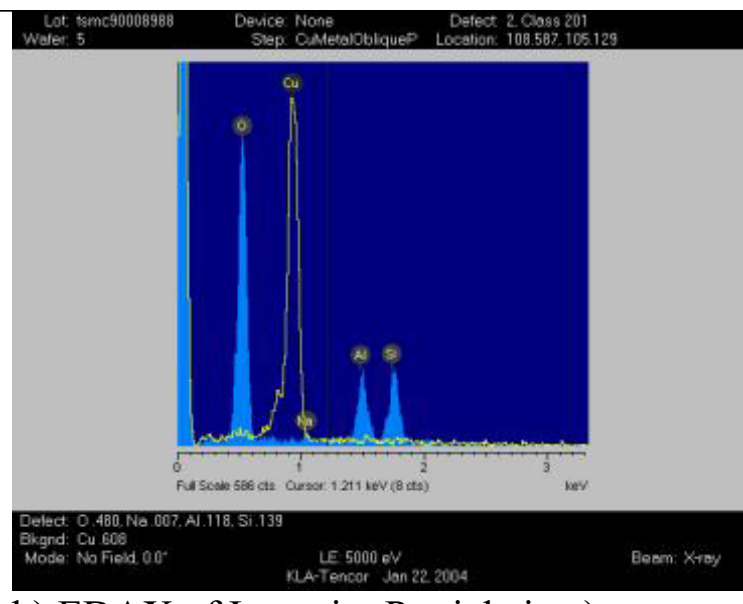

b) EDAX of Impurity Particle in a) 